\title{
Research on Beijing Easing Public Transport Congestion Based on Singapore
}

\author{
Hongchang An \\ Department of Safety Engineering, China Institute of Industrial Relations, Beijing, China
}

Email address:

anhongchang@126.com

\section{To cite this article:}

Hongchang An. Research on Beijing Easing Public Transport Congestion Based on Singapore. Humanities and Social Sciences. Vol. 4, No. 5, 2016, pp. 131-134. doi: 10.11648/j.hss.20160405.12

Received: July 17, 2016; Accepted: August 2, 2016; Published: August 21, 2016

\begin{abstract}
Singapore is one of the countries in the world that is recognized public traffic management well. Public transport congestion in Beijing is serious for everyone. Relevant governmental departments have taken some measures, but the effect is not obvious. Therefore, by combing public traffic management measures in Singapore, combining with public traffic management measures in Australia and referring to public traffic management in Beijing, public transport congestion in Beijing will be improved, and the traffic congestion in Beijing will be improved, and Beijing will be more beautiful, and better life in Beijing will be made according to the schemes for easing public transport congestion in Beijing.
\end{abstract}

Keywords: Public Transport, Congestion, Beijing, Singapore, Punctual Arrival, Bus First

\section{Introduction}

Traffic congestion in Beijing is obvious to all. Especially it is daunting during the peak hours, and the harms that it causes are well known. Relevant governmental departments have taken some measures, but the effect is not obvious. Successful foreign experiences show that the first priority of solving the traffic congestion is to solve the problem of public transport congestion. Public transport congestion in Beijing is serious for everyone such as overcrowded on the subway during the peak hours, crowded on the bus and a serious blockage during the rush hours. Solving traffic congestion in Beijing should also begin from the solution to public transport congestion in Beijing. To solve public transport congestion in Beijing is not only part of the solution to traffic congestion in Beijing, is also to solve the congestion problem in itself, also can attract non public transport to reduce travel and in turn help solve public transport congestion in Beijing, and this will form a virtuous circle. On the contrary, if the governments do not solve public transport congestion in Beijing, traffic congestion in Beijing and the congestion problem in itself will not be solved, this will not be able to attract non public transport to travel less, or even to encourage non public transport to travel more so as to increase public transport congestion in Beijing, and this will form a vicious circle. Public transport congestion in Beijing has come to the urgent situation, since 2016 Beijing governmental projects involving a number of related issues can be seen. The 2022 Winter Olympics will come to Beijing, it is now necessary to issue a warning: if the governments do not ease public transport congestion in Beijing as soon as possible, traffic and public transport in Beijing after the 2022 Winter Olympics is as bad as, or even worse than one after 2008 Olympic Games. If the governments want to take this as an opportunity to improve the traffic in Beijing, to improve the public transport in Beijing, they must find a series of measures of easing public transport congestion in Beijing as soon as possible, but cannot fear and wait for anything.

Traffic in Singapore is good, and their public transport has been recognized as good in the world. The author has stayed in Singapore for a week, and has a deep investigation of it. Learning from public transport management model in Singapore for Beijing to solve public transport congestion, and then solving a certain degree of traffic congestion in Beijing have a great value.

\section{Related Works}

Buying a vehicle is costly; the congestion charge is collected when driving a vehicle; branch road construction is paid attention to; green travel is encouraged; public transport is developed first; intelligent transport should be made [1].

High taxes on vehicle are taken; high rate policy is adopted 
on vehicle license plate; vehicle quota system and car holding license auction system are adopted; electronic road pricing system, weekend car and off peak vehicles system, red car system are adopted; public traffic of good quality, complete public transport, people-oriented public traffic management concept are vigorously developed [2].

Singapore attaches importance to the efficiency of urban traffic, enhances road traffic management, actively uses the price mechanism to adjust the vehicle ownership and use, to implement vehicle purchase tax policy, vehicle owning license management system and traffic jam fee for vehicle traffic demand management and road is set to a single line, parking construction is arranged and high parking fees are charged, in addition to the reasonable layout of the road network, development of public transport means [3].

The establishment of an integrated public transport system is people-oriented; the implementation of traffic and parking charge management is strictly controlled; vehicle quota and the collection of taxes and fees system are implemented to restrict on owning a car [4].

Quantity control, red car, car ownership certificate, the congestion charge, gas and vehicle license management are adopted [5].

Early scheme is the implementation of vehicle charging licensing restrictions; heavy attack scheme is the implementation of quota allocation of vehicles [6].

Bus is prominent, fare is reasonable, the service quality supervision is effective, land and transportation planning is scientific, traffic demand management is strict such as vehicle quota system, electronic toll collection system, parking and transfer system [7].

Through bus priority strategy, all public transports are planned under "the same roof" to realize an effective and seamless transition between each other, thus most of the urban traffic problem would be solved [8].

The subway is free before 7:45 AM, has discounted 0.5 Dollar within 7:45-8:30 [9].

The implementation of the comprehensive planning of urban transport and land use development is required; unified planning of bus lines and the scientific layout of line direction are needed; the implementation of bus priority is required; public transit transfer hub construction should be strengthened vehicle license management system and toll road management system should be implemented; humanized service demand should be provided; intelligent management is implemented to ensure that urban traffic is smooth and efficient to attract the public to choose bus travel and improve urban public transport sharing rate [10].

\section{Valuable Singapore Measures for Beijing to Ease Public Transport Congestion}

\subsection{Subway in Singapore}

For subway in Singapore, there are features below:
(1) Punctual arrival

Every subway is at the right time.

(2) Fare management

The subway is free before 7:45 AM, has discounted 0.5 Dollar within 7:45-8:30.

(3) Convenient transfer

A number of integrated public transport hubs are constructed; transfer facilities are convenient and people-oriented.

\subsection{Bus in Singapore}

For bus in Singapore, there are features below:

(1) Punctual arrival

Not only subway arrives on time, the bus is also very punctual. Buses are almost at the time of arrival. In order to ensure the arrival time, bus priority access is taken, the car traffic is limited, the use of a single line is done, and the supply of parking spaces is increased.

(2) Full coverage

The bus can reach any reachable place.

(3) Convenient transfer

There will be bus stop within every 400 meters.

(4) Reasonable fare

Reasonable fare can attract the public to choose public transport.

(5) Civilized riding

Queuing up in order to get on the bus, paying attention to health, and keeping the number of restrictions, the driver competent, illegal punishment are taken.

(6) Road management

Road specifications, clear signs are needed.

\section{The Idea of Easing Public Transport Congestion in Beijing Compared with Singapore}

\subsection{Subway in Beijing}

Compared with Singapore, the current subway in Beijing is much more developed. But there is still a gap in the quality of management.

Below are measures for Beijing easing subway congestion compared with Singapore:

(1) Punctual arrival

This can be done.

(2) Fare management

This approach is too rigid; the act from the original two $\mathrm{RMB}$ to now according to the mileage charges is simple. More reasonable fare strategy should be developed to disperse the flow of people.

(3) Convenient transfer

This is also a very gap, should do more optimization, build adequate free parking spaces in the relevant station.

\subsection{Bus in Beijing}

Below are measures for Beijing easing bus congestion 
compared with Singapore:

(1) Punctual arrival

This is the biggest problem in Beijing, is an important reason to give up the bus and drive car and ride subway. The first step of improving the public bus congestion is to arrive at the stop on time. For a bus first, the implementation of the private drivers being conscious to give way, being reminded to give way, being forced to give way is required; this still needs to guarantee the vehicle, buy and use high quality vehicles and related complete facilities and equipment, high quality drivers and driving civilization are required, and there are restrictions on the number of passengers.

(2) Full coverage

The government must adjust the layout of the bus lines, reduce the lines in the subway coverage area, and cover the area subway cannot cover. This is a very challenging task, but it is imperative.

(3) Convenient transfer

Optimization of transfer convenience with other public transportation, increasing the stop layout, the construction of enough free parking spaces surrounding the stop is needed.

(4) Reasonable fare

This is not too serious problem; the previous unreasonable price has been reversed.

(5) Civilized riding

Make more strict rules of the bus riding and strengthen the law enforcement.

(6) Road management

To strengthen the management of the road, the effective use of road resources, more use of a single line, road specifications, and clear signs is needed.

\section{The Schemes for Easing Public Transport Congestion in Beijing}

The schemes for easing public transport congestion in Beijing are planned according to the public traffic management models in Singapore and Australia. Australia is also one of the countries in the world whose public traffic management is recognized as well. The author has stayed in Sydney, Australia for one year and has a deep understanding of it. The schemes pay attention to both the inside and the outside.

\subsection{Measures from the Outside}

Reduce the number of the vehicles that enter into Beijing in the daytime from six to twenty. Concrete measures are:

First, define the boundary, for instance, with the sixth ring as the boundary.

Second, all vehicles are not allowed to enter into the sixth ring in the daytime from six to twenty besides the allowed vehicles such as military vehicles, or the half of the vehicles are not allowed to enter into the sixth ring in the daytime from six to twenty besides the allowed vehicles such as military vehicles. Especially, the coach buses passing the city should be prohibited to enter into the sixth ring in the daytime from six to twenty.

Third, the vehicles violating the ban regulations should be highly punished. No tooting; give way to buses; hand out the cards on which are written with ban regulations.

Last, four to eight large and free transfer and parking places should be arranged outside the sixth ring or in these places outside the sixth ring such as Zhuozhou, Gu'an, Yanjiao, Shunyi, Changping, Mentougou.

\subsection{Measures from the Inside}

\subsubsection{Measures for Subway}

For subway, reducing and dispensing passengers in the peak hours is main task. Concrete measures include: dispensing passengers by making use of ticket pricing mechanism and adjusting running mode, for instance, stopping at interval stops; taking some measures to restrict the number of passengers; providing people-oriented transfer; providing free parking spaces as enough as possible in certain stations by self-constructing, renting, collecting and imposing parking places.

\subsubsection{Measures for Bus}

For bus, every bus line has almost fixed total running time and the bus arrives at the certain stop at the concrete time. For this, some measures must be taken, such as:

Roads should be divided into main roads, secondary roads, and other roads. Different roads have different management mode, for instance, other roads must be single line, secondary roads cannot be parked on their sides, and main roads may be parked according to some conditions. Different roads have different speed set. Roads should be managed more standard and people-oriented. Road traffic signs are plenty and clear. Road traffic management is more intelligent. Main roads should be reduced exits and entrances or kept the enough distances between adjoining exit and entrance to avoid blockage.

Bus line should be planned again. Trolley buses and BRTs should be kept as unchanged as possible. But their total running time and every stop's arrival time should be first set. Trolley buses are increased unnecessarily. BRTs should be arranged in main roads as many as possible. In the city, every bus line should not exceed $25 \mathrm{~km}$, the distance of every two stops should not exceed $1 \mathrm{~km}$, some stops should close to the nearest subway station as near as possible, different buses cannot arrive at the same stop at the same time and should arrive at the same stop according to time orderly. In order to assure the buses can arrive at every stop on time, the first is that buses are in good state, which requires more and better maintenance and good quality, the second is that bus drivers are of good qualifying, the third is that other vehicles are not allowed to block buses by letting them be conscious to give way, be reminded to give way by voice or be forced to give way by videos and the buses should run on the set lane and cannot enter other lanes, the last is that things that block buses should be informed of traffic management organizations to find some means to avoid blockage before they appear. People can find a stop within 500 meters. 
Reduce the number of running vehicles in the daytime from six to twenty. Keeping the current restriction of vehicles is tolerable. The best or better is that the vehicles with nonlocal vehicle plates besides the allowed vehicles such as military vehicles cannot run in the daytime from six to twenty.

Any act that causes blockage to buses should be avoided. Pedestrians that are not within footway and non-motorized vehicles should give way to buses. Queue up in order to get on the bus, pay attention to health, and keep the number of restrictions. The blockage that polices cause also should be avoided.

In order to have more road resources, the governments should provide more parking spaces, even free parking spaces. New building should provide corresponding parking spaces. Existing parking spaces should be freely or partly freely open to people. More parking spaces are planned on the empty places. Cancel parking fee collectors and change them to be parking inspectors that inspect whether the vehicles park in standard and decide whether the parking vehicles are punished. The organizations that cause people to gather should take measures to provide enough free or partly free parking spaces.

Strengthen the punishment. If the vehicles occupy the way that the buses are running before and behind $50 \mathrm{~m}$ for a long time or the times that the vehicles violate traffic regulations exceed set times, pay higher punishment. Vehicles in fault or in an accident should be punished if they block the road for a long time longer than a set time.

\section{Conclusion}

Public transport in Beijing has obvious problems, and there are many factors to influence the public transport congestion. On the basis of adopting in priority some of the above mentioned important and practical measures in Singapore, and constantly improving the condition of the roads, guiding private vehicles to run in rules, strengthening all kinds of traffic participants' civilization traffic training, limiting the number of nonlocal vehicles according to the schemes for easing public transport congestion in Beijing will gradually ease the public transport congestion in Beijing, to make public transport in Beijing be like in Singapore as well, to make Beijing have better traffic, be with better traffic and other environment, create for the good, create a better life.

\section{Acknowledgement}

This paper is supported by General Research Project (14YY001) from China Institute of Industrial Relations.

\section{References}

[1] Lei Yin. Bus First and Traffic Congestion Fee Collecting. Xiamen Daily. 2015-7-9, A05.

[2] Yunxing Li. Revelation of Limited Vehicle Licensing Plate Post Age in Singapore for China to Manage Traffic Congestion. Science and Technology Vision. No. 32, 2015, pp. 168, 188.

[3] Hongbo Li. Practice of Solving Traffic Congestion in Urban Road--Measures of the Price Mechanism of Road Traffic Management in Singapore. Market Economy and Price. No. 12, 2014, pp. 55-57.

[4] Yuzhu Yi. People-oriented versus Limit and Control-_Experiences of Traffic Congestion Management in Singapore. China Construction. No. 10, 2014, pp. 52-55.

[5] Qiwen Lu, Chong Ren. Singapore Experience: the Use of Economic Levers to Alleviate Congestion. Policy Research and Exploration. No. 7, 2014, pp. 72-73.

[6] Chunjiang Yu. Urban Governance should Understand Public Feelings-C-Taking Traffic Congestion Control in Singapore for Example. Hangzhou (Quality Life). No. 12, 2013, pp. 69-70.

[7] Guoyao Pan, Jing Lu. Singapore: Urban Traffic Congestion Control Model. Transport Business China. No. 8, 2010, pp. 66-69.

[8] Feng Lu. Why Rare Traffic Congestion under One Car Every 10 Persons. Xinhua Daily. 2006-12-29, B01.

[9] Wei Wen. Decision-making not on the Shot in the Forehead-Crom Subway Congestion Management in Singapore Speaking. China Youth. No. 10, 2013, pp. 7.

[10] Zhengye Lu. Revelation of Singapore Urban Public Transport Management on Guangxi. Western China Communication Science and Technology. No. 12, 2012, pp. 73-76. 